\title{
Dampak Pemotongan Gaji pada Perusahaan dan pada Karyawan Selama Masa Pandemic Covid 19
}

\section{Putri Diana Sampe1*, Johnson Dongoran²}

1,2 Universitas Kristen Satya Wacana Salatiga, Indonesia

\section{ART ICLE INF O}

\section{Article history:}

Received August 16, 2021

Revised August 19, 2021

Accepted October 12, 2021

Available online October 25, 2021

Kata Kunci:

Pemotongan Gaji, Perusahaan,

Karyawan

Keywords:

Salary Deduction, Company,

Employee

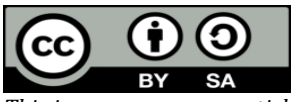

This is an open access article under the CC BY-SA license.

Copyright (C) 2021 by Author. Published by Universitas Pendidikan Ganesha.

\begin{abstract}
A B S T R A K
Pandemi covid-19 memberikan dampak negarif bagi prekonomian, salah satunya pada perusahaan yang mengambil tindakan pemotongan gaji bagi karyawan. Tujuan penelitian ini adalah untuk menganalisis dampak pemotongan gaji pada perusahaan dan pada karyawan selama masa pandemi covid 19. Jenis penelitian adalah penelitian kualitatif. Jumlah responden dalam penelitian ini adalah 10 responden yang terdiri dari satu pimpinan dan sembilan karyawan. Teknik pengambilan sampel menggunakan metode purposive sampling. Pendekatan yang digunakan dalam penelitian ini adalah pendekatan kualitatif. Jenis data yang digunakan dalam penelitian ini adalah data primer yang diperoleh langsung dari jawaban dari pimpinan dan karyawan yang dikumpulkan melalui kuesioner. Kuesioner yang digunakan adalah jenis kuesioner terbuka. Data dianalisis menggunakan teknik analisis deskriptif kualitatif. Hasil penelitian ini menunjukkan bahwa penurunan pendapatan karyawan akibat dari pemotongan gaji yaitu antara $15 \%$ hingga $20 \%$. Dampak pemotongan pada perusahaan mencakup dua hal yakni keuangan perusahaan khususnya dalam sisi pengeluaran yang juga diharapkan bisa menopang kestabilan perusahaan dan beban kerja karyawan dikurangi, sedangkan dampak pemotongan gaji pada karyawan diantaranya yaitu sulit dalam mengelola atau mengatur keuangan, kredit-kredit yang menunggak, kebutuhan karyawan tidak sepenuhnya terpenuhi, beban ekonomi yang semakin meningkat sementara gaji dipotong, motivasi kerja menurun, rasa disiplin yang menurun, acuh tak acuh terhadap pekerjaan, dan hasil kerja yang tidak maksimal.
\end{abstract}

A B S T RACT

The COVID-19 pandemic has had a negative impact on the economy, one of which is companies that take action to cut salaries for employees. The purpose of this study was to analyze the impact of salary cuts on the company and on employees during the covid 19 pandemic. The type of research is qualitative research. The number of respondents in this study were 10 respondents consisting of one leader and nine employees. The sampling technique used purposive sampling method. The approach used in this study is a qualitative approach. The type of data used in this study is primary data obtained directly from answers from leaders and employees collected through questionnaires. The questionnaire used is an open questionnaire. Data were analyzed using qualitative descriptive analysis techniques. The results of this study indicate that the decrease in employee income due to salary cuts is between 15\% to 20\%. The impact of cuts on the company includes two things, namely the company's finances, especially on the expenditure side which is also expected to support the stability of the company and the workload of employees is reduced, while the impact of salary cuts on employees includes difficulty in managing or managing finances, credits in arrears, employee needs. not fully met, increasing economic burden while salary cuts, decreased work motivation, decreased sense of discipline, indifferent to work, and work results that are not optimal.

\section{PENDAHULUAN}

Pada masa pandemi Covid-19 dan sekarang ini dunia sudah berada pada era New Normal baik itu dalam segi pola hidup masyarakat sehari-hari sampai dengan lingkungan pekerjaan, pada saat mulainya pandemi Covid-19 ini sampai sekarang banyak krisis dan kerugian yang dirasakan terutama dalam bidang ekonomi (Anwar, 2020; Muhyiddin, 2020). Kerugian ini dimulai dari bidang kesehatan tetapi dengan cepat merambah ke bidang ekonomi, situasi seperti ini belum pernah dirasakan sebelumnya dan tidak ada yang membayangkan akan separah ini sehingga berdampak ke berbagai pihak termasuk perusahaan (Nasution et al., 2020a; Pakpahan, 2020). Dengan adanya situasi seperti ini perusahaan diharuskan segera mengambil keputusan terbaik demi keberlangsungan perusahaan tersebut, dan banyak perusahaan-perusahaan mengambil keputusan untuk memotong gaji karyawannya serta pilihan yang paling buruk yaitu pemutusan hubungan kerja (Anwar,2020). PT Mega Auto Finance atau yang disingkat dengan sebutan MAF adalah perusahaan yang bergerak di bidang pembiayaan kendaraan bermotor roda dua yang didirikan pada tahun 2007. Dengan dukungan sekitar 5.000 orang karyawan di seluruh Indonesia, PT MAF fokus dalam 
memberikan pelayanan pembiayaan sepeda motor Yamaha. PT MAF melakukan pemotongan gaji pada karyawannya jika tidak masuk kerja, tetapi dimasa pandemi Covid-19 ini banyak perusahaan melakukan pemotongan gaji salah satunya yaitu PT MAF Cabang Palopo. Tetapi, harus dengan kesepakatan dengan para pekerjanya. Perusahan hanya bisa memotong gaji pekerjanya paling tinggi $50 \%$ dari gaji yang diterima pekerja. Jika Perusahaan memotong gaji pekerjanya lebih dari 50\% karena COVID-19, maka akan mendapat hukuman administratif yaitu: teguran tertulis,pembatasan kegiatan usaha, penghentian sementara sebagaian atau seluruh alat produksi, serta kegiatan usaha tidak berjalan (Sandi,2020).

Dampak ekonomi yang terjadi saat pandemi Covid-19 melanda yang mengakibatkan roda perekomomian Indonesia mengalami stagnasi hingga mengalami kemerosotan yang cukup signifikan. Negara mengalami kerugian akibat pendapatan Negara mengalami penurunan sedangkan anggaran belanja melonjak tinggi untuk mengatasi kondisi darurat pandemic Covid-19 (Nasution et al., 2020b; Pakpahan, 2020). Bukan hanya Negara, sebagian besar perusahaan baik dari skala besar, menengah, maupun kecil mengalami dampak yang tidak jauh berbeda. Perusahaan memenuhi kebutuhan setiap tahun berbeda dan terus bertambah membuat investor harus memikirkan dengan matang dalam memutuskan kebijakan pemotongan gaji yang dilakukan oleh perusahaannya (Anggardini dan Affandi,2017). Jika di terapkan setiap bulan maka karyawan akan mengalami kekurangan dalam bidang ekonomi. Dan tidak jarang jika setiap harinya resistensi yang dilakukan pekerja akan terus berubah-ubah dan dapat membahayakan perusahaan itu sendiri.

Beberapa temuan menyatakan sejumlah tempat wisata tutup selama bulan Maret sampai dengan Juni 2020 yang mempengaruhi turunnya pendapatan pajak wisata dan hiburan serta berpengaruh juga terhadap kinerja karyawan pariwisata seperti pemotongan gaji dan insentif tidak dibayar selama masa COVID-19 serta pemutusan hubungan kerja (soehardi et al. 2020). Dari beberapa pendapat diatas mereka hanya fokus pada dampak bagi karyawan saja seperti kinerja karyawan menurun dan resistensi dikarenakan sejumlah tempat wisata tutup selama bulan Maret sampai dengan Juni 2020 yang mempengaruhi turunnya pendapatan pajak wisata dan hiburan serta berpengaruh juga terhadap kinerja karyawan pariwisata seperti pemotongan gaji dan insentif tidak dibayar selama masa COVID-19 serta pemutusan hubungan kerja (PHK). Dari beberapa pendapat diatas mereka hanya fokus pada dampak bagi karyawan saja seperti kinerja karyawan menurun dan resistensi karyawan yang berubah-ubah, sedangkan penelitian ini meneliti dampak pemotongan gaji pada karyawan dan perusahaan. Dalam penelitian ini bertujuan untuk menganalisis tingkat pemotongan gaji karyawan gaji karyawan bagi perusahaan.Manfaat penelitian ini yaitu, untuk perusahaan dari pemotongan gaji yaitu bisa mengurangi pengeluaran perusahaan, sebagai pertimbangan untuk tidak melakukan PHK terhadap karyawan. Untuk karyawan pemotongan gaji dilakukan agar karyawan tetap bekerja dan tidak di PHK walaupun gaji yang diterima tidak sepenuhnya. Bagi peneliti selanjutnya, sebaiknya mencari variabel-variabel yang belum pernah diteliti sebelumnya agar peneliti selanjutnya lagi memiliki referensi yang banyak, menambah pengetahuan dan referensi tambahan bagi peneliti lain terkait dampak pemotongan gaji baik bagi karyawan maupun bagi perusahaan.

\section{METODE}

Metoda analisis data yang akan digunakan di dalam penelitian ini yaitu metode kualitatif yaitu penelitian yang bersifat deskriptif dan cenderung menggunakan analisis untuk memahami fenomena apa yang dialami oleh karyawan dan perusahaan Al-Ghazaruty (2009). Tempat pengambilan data dilakukan di PT. Mega Auto Finance (MAF) Cabang Palopo. Adapun informan yang akan saya wawancarai yaitu kepala cabang PT. Mega Auto Finance (MAF) cabang Palopo (Novianus) dan Sembilan karyawan dari PT. Mega Auto Finance (MAF) cabang Palopo. Dalam menentukan narasumber, peneliti menggunakan teknik purposive sample, yaitu cara pengambilan subjek bukan didasarkan atas dasar asal pilih tetapi didasarkan atas adanya tujuan tertentu Arikunto (2006). Kriteria pemilihan informan adalah mereka yang mengalami dampak dari pemotongan gaji pada masa pandemic covid 19. Pengumpulan data metode ini menggunakan data primer dan sekunder. Data primer yaitu data primer adalah data yang dikumpulkan melalui pihak pertama, biasanya dapat melalui wawancara, kuesioner dan lain-lain. Data sekunder dalam penelitian ini adalah data yang diperoleh dari jurnal-jurnal. Pengambilan data penelitian adalah pembagian kuesioner dengan informan. Pedoman kuesioner yang diberikan adalah tujuh pertanyaan guna menjawab permasalahan peneliti tentang dampak pemotongan gaji pada perusahaan dan pada karyawan selama masa pandemic covid-19. Setelah data yang diperlukan sudah terkumpul melalui wawancara, kemudia informasi dan keterangan yang diterima dalam penelitian ini akan menjadi data untuk dianalisis menggunakan metode deskriptif analisis, deskriptif analisis merupakan metode analisis data di mana penulis memaparkan semua data yang sudah diperoleh dari hasil wawancara untuk kemudian untuk menganalisis sesuai dengan permasalahan dan tujuan penelitian yang selanjutnya akan disusun dalam bentuk laporan ilmiah. 


\section{HASIL DAN PEMBAHASAN}

Kuesioner disebarkan kepada pimpinan dan karyawan dari PT Mega Auto Finance (MAF) Cabang Palopo pada tanggal 1 Juli 2021 dan diambil pada tanggal 14 Juli 2021. Responden dalam penelitian ini terdiri dari 10 orang yakni satu pimpinan dan sembilan karyawan yang masing-masing enam pria dan empat wanita dengan tingkat pendidikan delapan strata satu dan dua SMA. Responden yang berusia di atas dua puluh tahun berjumlah dua orang, yang berusia di atas tiga puluh tahun berjumlah lima orang, dan yang berusia di atas empat puluh tahun berjumlah tiga orang. Dampak pemotongan gaji pada perusahaan, dalam kondisi pandemi seperti sekarang ini dimana perusahaan harus mengambil kebijakan yaitu melakukan pemotongan gaji pada karyawan agar dapat mempertahankan kestabilan keuangan perusahaan. Dalam hal ini kebijakan pemotongan gaji berdampak terhadap keuangan perusahaan khususnya dalam sisi pengeluaran yang bisa menopang keuangan karena gaji karyawan tidak dibayar penuh. Saat sekarang ini banyak terjadi pemberlakuan pemotongan gaji dan karyawan yang tidak mendapatkan gaji sesuai dengan pekerjaan yang diberikan. Tetapi seiring dengan pemberlakuan kebijakan pemotongan gaji pihak PT Mega Auto Finance juga mengurangi beban kerja karyawan karena gaji yang dibayarkan tidak sama jika mereka bekerja full time. Dengan demikian dapat disimpulkan bahwa dampak pemotongan gaji pada perusahaan mencakup dua hal yakni keuangan perusahaan tidak berkurang dan beban kerja karyawan dikurangi.

Pendapatan karyawan menurun akibat dari kebijakan pemotongan gaji yang diterapkan oleh perusahaan. Penurunan pendapatan karyawan dari PT Mega Auto Finance bervariasi diantaranya dua orang $15 \%$,dua orang $17 \%$,tiga orang $18 \%$,dan tiga orang lagi $20 \%$. Dengan demikian penurunan pendapatan karyawan akibat dari pemotongan gaji yaitu antara 15\%-20\%. Dengan adanya pemotongan gaji pasti sangat berdampak kepada kehidupan keluarga karyawan, penurunan pendapatan ini tentunya akan sangat mengganggu keuangan keluarga karena disisi lain, value elemen elemen pengeluaran keluarga malah bertambah. Adapun dampak dari pemotongan gaji pada PT Mega Auto Finance terhadap karyawan yaitu sulit dalam mengelola atau mengatur keuangan oleh dua orang, kredit-kredit yang menunggak oleh tiga orang, kebutuhan karyawan tidak sepenuhnya terpenuhi oleh tiga orang, dan beban ekonomi yang semakin meningkat sementara gaji dipotong oleh dua orang. Gaji merupakan salah satu sumber semangat karyawan karena jika gaji dipotong secara otomatis akan mempengaruhi kinerja karyawan, semangat tidaknya karyawan bisa juga disebabkan oleh besar kecilnya gaji yang diterima. Berdasarkan hasil penelitian, dampak dari pemotongan gaji diantaranya yaitu motivasi kerja menurun dijawab oleh empat orang, rasa disiplin yang menurun oleh dua orang, acuh tak acuh terhadap pekerjaan oleh dua orang, dan hasil kerja yang tidak maksimal oleh dua orang. Sehingga dapat disimpulkan bahwa dampak pemotongan gaji pada karyawan yaitu penurunan pendapatan, sulit dalam mengelola atau mengatur keuangan, kreditkredit yang menunggak, kebutuhan karyawan tidak sepenuhnya terpenuhi, beban ekonomi yang semakin meningkat sementara gaji dipotong, motivasi kerja menurun, rasa disiplin yang menurun, acuh tak acuh terhadap pekerjaan, dan hasil kerja yang tidak maksimal. Potong gaji menimbulkan seseorang merasa tempat bekerja mereka tidak adil. Potong gaji dan PHK berefek negatif dampak psikologis dari waktu ke waktu dapat diterjemahkan menjadi masalah kesehatan fisik (Sulastri, 2021).

Berdasarkan keseluruhan analisis deskriptif, maka hasil penelitian yang dilakukan, terdapat dampak pemotongan gaji pada perusahaan dan pada karyawan pada PT Mega Auto Finance Cabang Palopo akibat dari pandemic covid-19. Kondisi perkenomian saat ini dikarenakan wabah Covid-19 menyebar keseluruh dunia yang mengakibatkan banyak perusahaan terganggu dalam operasioanalnya tentu memilki dampak pada kemampuan pengusaha untuk memenuhi kewajiban membayarkan gaji secara penuh terhadap karyawan maka dengan demikian pihak perusahaan melakukan kebijakan pemotongan gaji (Zia, 2020). Dan dampaknya bagi perusahaan mencakup dua hal yakni keuangan perusahaan khususnya dalam sisi pengeluaran yang juga diharapkan bisa menopang kestabilan perusahaan dan beban kerja karyawan dikurangi. Pemotongan gaji menyebabkan keterbatasan dan kesulitan dalam memenuhi kebutuhan hidup pribadi dan keluarga menjadi pemicu stres. Juga, karena persediaan makanan terbatas, mereka yang memiliki persediaan ragu-ragu untuk membagi persediaan mereka untuk kebutuhan masa depan, hal inilah yang menjadi dasar pemicu kesehatan mental karyawan memburuk seiring berjalannya waktu.

Dari sudut pandang organisasi, memberikan gaji merupakan salah satu faktor penting dalam meningkatkan kepuasan kerja, memotivasi karyawan, merangsang karyawan baru yang berkualitas untuk memasuki organisasi, mempertahankan karyawan yang ada, dan meningkatkan kinerja karyawan serta produktivitas perusahaan (Agrawal et al.,2012; Haerani et al., 2020; Antonakas et al., 2020). Sejalan dengan itu Gaji merupakan salah satu unsur yang penting yang dapat mempengaruhi kinerja, prestasi dan loyalitas karyawan, sebab gaji adalah alat untuk memenuhi berbagai kebutuhan pegawai, sehingga dengan gaji yang diberikan karyawan akan termotivasi untuk bekerja lebih giat. (Bakri, 2020; Hasni, 2020; Mangkunegara, 2011). Tetapi karena adanya pandemic covid-19 secara otomatis perusahaan memberlakukan kebijakan pemotongan gaji yang memberi dampak pada karyawan yakni penurunan pendapatan dengan kisaran 
antara 15\%-20\%, sulit dalam mengelola atau mengatur keuangan, kredit-kredit yang menunggak, kebutuhan karyawan tidak sepenuhnya terpenuhi, beban ekonomi yang semakin meningkat sementara gaji dipotong, motivasi kerja menurun, rasa disiplin yang menurun, acuh tak acuh terhadap pekerjaan, dan hasil kerja yang tidak maksimal.

Temuan penelitian ini diperkuat dengan penelitian sebelumnya yang mengemukakan bahwa perusahaan, melakukan efesiensi dengan memberlakukan pemotongan gaji guna mengurangi pengeluaran keuangan perusahaan agar bisa bertahan ditengah pandemi (Ropidin \& Riyanto, 2020). Salah satu dampak lain dari pandemi Covid-19 adalah pengurangan gaji pegawai yang dilakukan oleh beberapa perusahaan. Hal ini menimbulkan dampak-dampak lain seperti penurunan motivasi, kemalasan, dan hasil kerja yang tidak maksimal (Juniantara \& Rianan, 2020). Pandemi covid 19 mengakibatkan banyak karyawan yang mengalami penurunan penghasilan, dan sangat memukul keuangan keluarga karyawan sehingga harus mengurangi beberapa item pengeluaran (Yuli Siyamto \& Asron Saputra, 2021). Hasil penelitian baru yaitu beban kerja karyawan menurun, sulit dalam mengelola atau mengatur keuangan, kredit-kredit yang menunggak, beban ekonomi yang semakin meningkat sementara gaji dipotong, rasa disiplin yang menurun, acuh tak acuh terhadap pekerjaan.

\section{SIMPULAN}

Berdasarkan hasil penelitian dan pembahasan diatas maka dapat disimpulkan bahwa Dampak pemotongan gaji pada perusahaan mencakup dua hal yakni keuangan perusahaan khususnya dalam sisi pengeluaran yang juga diharapkan bisa menopang kestabilan perusahaan dan beban kerja karyawan dikurangi. Dampak pemotongan gaji pada karyawan yakni penurunan pendapatan dengan kisaran antara 15\%-20\%, sulit dalam mengelola atau mengatur keuangan, kredit-kredit yang menunggak, kebutuhan karyawan tidak sepenuhnya terpenuhi, beban ekonomi yang semakin meningkat sementara gaji dipotong, motivasi kerja menurun, rasa disiplin yang menurun, acuh tak acuh terhadap pekerjaan, dan hasil kerja yang tidak maksimal. Keterbatasan penelitian ini adalah jumlah responden hanya 10 orang yakni satu pimpinan dan sembilan karyawan dari total sekitar 20 orang karyawan disebabkan oleh banyak karyawan yang bekerja dari rumah karena diadakanya Work From Home guna mengurangi penyebaran covid 19. Saran untuk peneliti selanjutnya yaitu perusahaan lebih memperhatikan kebijakan pemotongan gaji kepada karyawan agar tidak mempengaruhi hasil kerja karyawan. Dan peneliti selanjutnya bisa menggunakan hasil penelitian baru yaitu beban kerja karyawan menurun, sulit dalam mengelola atau mengatur keuangan, kredit-kredit yang menunggak, beban ekonomi yang semakin meningkat sementara gaji dipotong, rasa disiplin yang menurun, acuh tak acuh terhadap pekerjaan untuk diolah dengan metode kualitatif atau kuantitatif.

\section{DAFTAR PUSTAKA}

Anwar, M. (2020). Dilema PHK dan Potong Gaji Pekerja. 'Adalah, 4(1), 173-178.

Bakri. (2020). Implementasi Sistem Informasi Akuntansi Penggajian dan Dampaknya Terhadap Kinerja Karyawan pada Bank Muamalat Cabang Gorontalo. Al-Buhuts, 16(1), 93-106.

Dwi Anggardini, T. (2016). Resistensi Karyawan Minimarket Terhadap Kebijakan Pemotongan Gaji Bulanan Sebagai Bentuk Ganti Rugi Barang Stock Opname. Paradigma, 5(1), 12.

Hasni, N. (2020). Pengaruh Gaji Terhadap Peningkatan Kinerja Karyawan. IIdikti9.Id, 4(Oktober), 50-59. http://journal.lldikti9.id/Ekonomika Vol 4, No, 2, Oktober 2020, pp. 50-59 p-ISSN:2088-9003 dan e-ISSN: 2685-6891.

Mangkunegara, P. A. (2011). Pengaruh Kompensasi Terhadap Kinerja Karyawan Di Pt. Global (Pt.Gm). Jurnal Ilmiah MEA (Manajemen, Ekonomi, \& Akuntansi), 3(2), 184-190. https: //doi.org/10.31955/mea.vol3.iss2.pp18.

Muhyiddin. (2020). Covid-19, New Normal, dan Perencanaan Pembangunan di Indonesia. Jurnal Perencanaan Pembangunan: The Indonesian Journal of Development Planning, 4(2), 240-252. https://doi.org/10.36574/jpp.v4i2.118.

Nasution, D. A. D., Erlina, E., \& Muda, I. (2020a). Dampak Pandemi COVID-19 terhadap Perekonomian Indonesia. Jurnal Benefita, 5(2), 212. https://doi.org/10.22216/jbe.v5i2.5313.

Nasution, D. A. D., Erlina, \& Muda, I. (2020b). Dampak Pandemi COVID-19 terhadap Perekonomian Indonesia. Jurnal Benefita, 5(2), 212 - 224. https: //doi.org/10.22216/jbe.v5i2.5313.

Nilamsari, N. (2014). Memahami Studi Dokumen Dalam Penelitian Kualitatif. Wacana, 13(2), 177-181.

Pakpahan, A. K. (2020). COVID-19 dan Implikasi Bagi Usaha Mikro, Kecil, dan Menengah. Jurnal Ilmiah Hubungan Internasional, 20(April), 59-64. https://doi.org/10.26593/jihi.v0i0.3870.59-64.

Riyanto, S., \& Ropidin. (2020). Dampak Pemutusan Hubungan Kerja Pada Perusahaan Farmasi Terkait 
COVID-19 Di Indonesia. Jurnal Syntax Transformation, 5(1), 1-8. https://doi.org/10.46799/jurnal syntax transformation.v1i5.63.

Sandi, F. (2020). Gara - gara corona gajimu di potong, memang boleh? In news (https://ww).

Saputra, Y. S. A. (2021). Analisis Keuangan Keluarga di Masa Pandemi Covid 19. Snistek, 3(September), 162167. http://ejournal.upbatam.ac.id/index.php/prosiding/article/view/3632.

Soehardi, S., Permatasari, D. A., \& Sihite, J. (2020). Pengaruh Pandemik Covid-19 Terhadap Pendapatan Tempat Wisata dan Kinerja Karyawan Pariwisata di Jakarta. Jurnal Kajian Ilmiah, 1(1), 1-14. https://doi.org/10.31599/jki.v1i1.216.

Sukirman, S. (2016). Pengembangan Kewirausahaan Melalui Peningkatan Kinerja Karyawan. Jurnal Ekonomi Dan Bisnis, 17(1), 135. https://doi.org/10.24914/jeb.v17i1.243.

Sulastri, S. (2021). Pengaruh Pemutusan Hubungan Kerja (PHK) dan Potong Gaji Terhadap Kesehatan Mental Karyawan UMKM di Lampung Timur pada Era Pandemi Covid-19. Jurnal Manajemen \& Bisnis Kreatif, $7(1), \quad 12$. https://journal.ubpkarawang.ac.id/index.php/Manajemen/article/view/1943.

Yahya, A., Balgies, S., Eka, A. A., \& Kumaya, J. R. (2020). Dampak Pandemi COVID-19 Bagi Pekerja "PHK, Pemotongan Gaji, dan Motivasi Kerja." Jurnal Psikologi Wijaya Putra, 1(2), 1-10. http://jurnal.uwp.ac.id/fpsi/index.php/psikowipa/article/view/34.

Zia, H. (2020). Kajian Hukum Ketenagakerjaan Terhadap Pemotongan Gaji Karyawan Karena Perusahaan Terdampak Covid-19. DATIN LAW JURNAL, 1(2). https://doi.org/10.36355/dlj.v1i2.450. 